\title{
Synergistic antitumor efficacy against the EGFRvIII+HER2+ breast cancers by combining trastuzumab with anti-EGFRvIII antibody $\mathrm{CH} 12$
}

\author{
Wen Xu' ${ }^{1,2, *}$, Yanyu Bi ${ }^{2, *}$, Jiqin Zhang ${ }^{2}$, Juan Kong ${ }^{2}$, Hua Jiang ${ }^{2}$, Mi Tian ${ }^{2}$, Kesang $\mathbf{L i}^{2}$, \\ Biao Wang ${ }^{2}$, Cheng Chen' ${ }^{2}$ Fei Song ${ }^{2}$, Xiaorong Pan², Bizhi Shí2, Xianming Kong², \\ Jianren $\mathbf{G u}^{2}$, Xiumei $\mathrm{Cai}^{1}$ and Zonghai $\mathbf{L i}^{2}$ \\ ${ }^{1}$ Medical School of Fudan University, Shanghai, China \\ 2 State Key Laboratory of Oncogenes \& Related Genes, Shanghai Cancer Institute, Renji Hospital, Shanghai Jiaotong \\ University School of Medicine, Shanghai, China \\ * These authors have contributed equally to this article \\ Correspondence to: Zonghai Li, email: Zonghaili@shsmu.edu.cn \\ Xiumei Cai, email: caixioum@163.com
}

Keywords: EGFRvIll+HER2+ breast cancers, EGFRVIII, CH12, trastuzumab resistance, STAT3

Received: June 10,2015 Accepted: September 17, $2015 \quad$ Published: October 14, 2015

This is an open-access article distributed under the terms of the Creative Commons Attribution License, which permits unrestricted use, distribution, and reproduction in any medium, provided the original author and source are credited.

\section{ABSTRACT}

Although Trastuzumab, an anti-HER2 antibody, benefits certain patients with HER2-overexpressing breast cancer, de novo or acquired trastuzumab resistance remains a haunting issue. EGFRvIII, co-expressing with HER2 in some breast tumors, indicates a poor clinical prognosis. However, the role of EGFRvIII in the function of trastuzumab is not clear. Here, we demonstrated that EGFRvIII overexpression contributed to de novo trastuzumab resistance and the feedback activation of STAT3 caused by trastuzumab also resulted in acquired resistance in EGFRvIII+HER2+ breast cancers. CH12, a highly effective anti-EGFRvIII monoclonal antibody that preferentially binds to EGFRvIII, significantly suppressed the growth of EGFRvIII ${ }^{+} \mathrm{HER2}^{+}$breast cancer cells in vitro and in vivo. Importantly, $\mathrm{CH}_{12}$ in combination with trastuzumab had a synergistic inhibitory effect on EGFRvIII ${ }^{+}$HER2 $^{+}$ breast cancers in vitro and in vivo via attenuating the phosphorylation of EGFR and HER2 and their downstream signal pathways more effectively and reversing STAT3 feedback activation. Moreover, the combination therapy suppressed angiogenesis and induced cell apoptosis significantly. Together, these results suggested a synergistic efficacy of the combination of trastuzumab with $\mathrm{CH}_{12}$ against EGFRvIII ${ }^{+} \mathrm{HER2}^{+}$breast cancers, which might be a potential clinical application in the future.

\section{INTRODUCTION}

Human epidermal growth factor receptor 2 (HER2), a receptor tyrosine kinase (RTK) that regulates cell growth and differentiation signaling pathways, is highly overexpressed in approximately $20 \%$ to $25 \%$ of breast cancers, leading to an aggressive tumor phenotype and a dismal prognosis $[1,2]$. Trastuzumab, a humanized antibody targeting HER2, shows considerable clinical efficacy and extends the overall survival of certain patients with HER2-overexpressing breast cancer [35]. However, the overall response rate to trastuzumab- containing therapies remains modest: $\sim 26 \%$ when used as a single therapy and $40-60 \%$ when used in combination with systemic chemotherapy [5-8]. Many patients do not respond to initial trastuzumab treatment (de novo resistance), and many trastuzumab-responsive patients develop resistance after continuous treatment (acquired resistance) $[9,10]$. Two major categories of trastuzumab resistance mechanisms have been proposed: (I) De novo resistance due to genetic alterations of receptor tyrosine kinases (RTKs) and their downstream signaling targets, such as aberrant activation of the PI3K/AKT pathway due to phosphatase and tensin homolog (PTEN) deficiency 
or PIK3CA gene activating mutations $[11,12]$, and the accumulation of truncated HER2 receptors ( $p 95$ HER2) that lack the trastuzumab-binding domain [13]; and (II) acquired resistance primarily due to the acquisition of alternative RTK or feedback signal activation that compensate for HER2 inhibition after trastuzumab treatment [14-16].

EGFR, an essential RTK, playing an vital role in cell differentiation, proliferation, and survival in a number of human cancers, also contribute to both de novo and acquired trastuzumab resistance [14, 17]. Accumulating reports have demonstrated that EGFRvIII, the most common EGFR mutant forms with constitutively activated kinase domain [18, 19], expresses in various human cancers, including breast cancer, and it has not been detected in normal adult human tissue [20, 21]. EGFRvIII expression was detected in approximately 5\% of primary breast cancer cases and contributes to cancer stem cell phenotypes in invasive breast carcinomas [21]. Furthermore, approximately $40 \%$ of HER2-positive primary breast tumors were found to co-express EGFRvIII, and, even more striking, $75 \%$ of HER2-positive metastatic lymph node specimens co-expressed EGFRvIII [22].

EGFRvIII is posited to be involved in tumorigenicity, invasiveness, and metastasis in breast cancers [22-24]. Several strategies against EGFRvIIIpositive tumors have been explored. For instance, antiEGFRvIII antibodies, such as mAb 806 and CH12, which selectively bind to a cancer-specific epitope of EGFR or EGFRvIII, have been demonstrated to be capable of efficiently inhibiting the growth of EGFRvIII-positive tumor xenografts $[21,25,26]$. However, it needs to be determined whether these antibodies have efficacy against breast tumors with EGFRvIII overexpression.

Considering the co-expression of HER2 and EGFRvIII in breast cancers, we predicted that HER2 and EGFRvIII might cooperate for tumor growth, and EGFRvIII expression might contribute to trastuzumab resistance. However, to date, no treatment strategies have been explored on EGFRvIII ${ }^{+} \mathrm{HER} 2^{+}$breast cancers. Therefore, in this study, we examined the combination effect of trastuzumab and $\mathrm{CH} 12$ on the EGFRvIII ${ }^{+} \mathrm{HER} 2^{+}$ breast cancer cells and the molecular mechanisms underlying their antitumor effects.

\section{RESULTS}

\section{EGFRvIII overexpression decreased the sensitivity of breast cancers to trastuzumab}

The EGFRvIII encoding sequence was introduced into the HER2-positive breast cancer cell lines BT474 and SKBR3, and the established EGFRvIII ${ }^{+} \mathrm{HER}^{+}$cells (FigureS1) were less sensitive to trastuzumab than their parental cells in vitro (Figure 1A). Furthermore, the antitumor efficacy of trastuzumab in BT474-EGFRvIII xenografts in nude mice was slightly weaker than that in parental BT474 model (Figure 1B). The inhibition rate of trastuzumab at a concentration of $2 \mathrm{mg} / \mathrm{kg}$ was $51 \%$ in BT474-parental xenograft, while it was $43.7 \%$ in BT474EGFRvIII model $(P<0.01)$.

To determine the molecular mechanism underlying EGFRvIII-mediated trastuzumab resistance, the downstream signaling of EGFR was analyzed. In

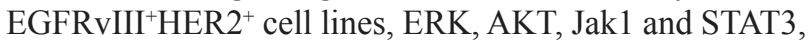
were activated compared with EGFRvIII-HER2 ${ }^{+}$cell lines (Figure 1C and 1D). After trastuzumab treatment, both AKT and ERK phosphorylation were less downregulated while Jak1 and STAT3 phosphorylation were unregulated more obviously in EGFRvIII ${ }^{+} \mathrm{HER} 2^{+}$than in EGFRvIII$\mathrm{HER}^{+}$cancer cell lines (Figure $1 \mathrm{C}$ and 1D). Together, EGFRvIII overexpression might decrease the sensitivity of breast cancer cells to trastuzumab via constitutively activating EGFR downstream signals including ERK, AKT, and Jak1/STAT3.

\section{STAT3 activation contributed to acquired trastuzumab resistance in EGFRvIII $^{+} \mathrm{HER2}^{+}$ breast cancer}

To determine the role of STAT3 in trastuzumab resistance in EGFRvIII ${ }^{+} \mathrm{HER} 2^{+}$breast cancers, the STAT3 inhibitor BP-1-102 was applied together with trastuzumab to treat breast cancer cells. The results illustrated that the combination of BP-1-102 and trastuzumab significantly enhanced the antitumor effect of trastuzumab on BT474EGFRvIII and SKBR3-EGFRvIII (Figure 2A) cells. The similar results were also observed in the combination of STAT3 siRNA with trastuzumab (Figure S2). In the combination group, STAT3 phosphorylation was significantly inhibited, and nuclear translocation of STAT3 was obviously reduced (Figure 2B and 2C). Other EGFR downstream signals activated constitutively by EGFRvIII were not obviously affected (Figure 2B). These results further demonstrated that STAT3 activation contributed to trastuzumab resistance in EGFRvIII ${ }^{+} \mathrm{HER} 2^{+}$breast cancer cells.

\section{CH12 significantly suppressed the growth of EGFRvIII ${ }^{+} \mathrm{HER2}^{+}$breast cancers in vitro and in vivo}

To determine whether an EGFRvIII-targeted strategy could be applied in breast cancer therapy, the anti-EGFRvIII monoclonal antibody CH12 was applied to treat $\mathrm{EGFRvIII}^{+} \mathrm{HER} 2^{+}$breast cancer cells. In vitro growth inhibition effect of $\mathrm{CH} 12$ was examined. The results shown in Figure 3A indicated that $\mathrm{CH} 12$ inhibited the growth of BT474-EGFRvIII and SKBR3-EGFRvIII 
cells in a dose-dependent manner. The antitumor effect of $\mathrm{CH} 12$ was further evaluated in established BT474EGFRvIII tumor models. As shown in Figure 3B, CH12 significantly inhibited the growth of BT474-EGFRvIII xenografts with an inhibition rate of $41 \%$ at a dose of 10 $\mathrm{mg} / \mathrm{kg}$ and $74 \%$ at a dose of $25 \mathrm{mg} / \mathrm{kg}$ on day 35 after the first administration (Figure 3B). Further study revealed that $\mathrm{CH} 12$ could obviously inhibit phosphorylation of EGFR, AKT, Jak1 and STAT3 (Figure 3C and 3D). Together, CH12 significantly suppressed the growth of EGFRvIII ${ }^{+} \mathrm{HER}^{+}$breast cancers in vitro and in vivo via inhibiting EGFR downstream signals.

\section{Combination of trastuzumab with $\mathrm{CH} 12$ synergistically inhibited the growth of EGFRvIII $^{+} \mathrm{HER2}^{+}$breast cancer cells in vitro and in vivo}

According to the efficacy of $\mathrm{CH} 12$ and the inhibition effect against ERK, AKT and Jak1/STAT3 pathway in EGFRvIII ${ }^{+} \mathrm{HER}^{+}{ }^{+}$breast cancers, we wondered whether
(A)

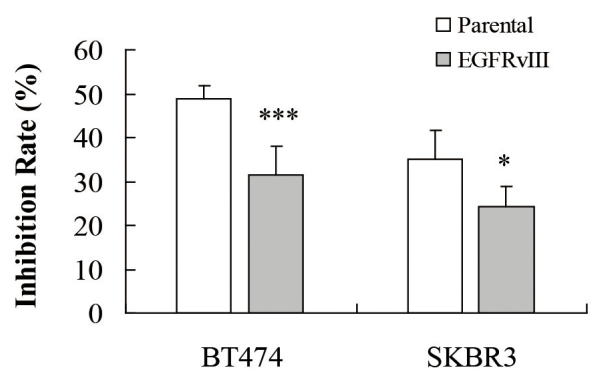

(C)

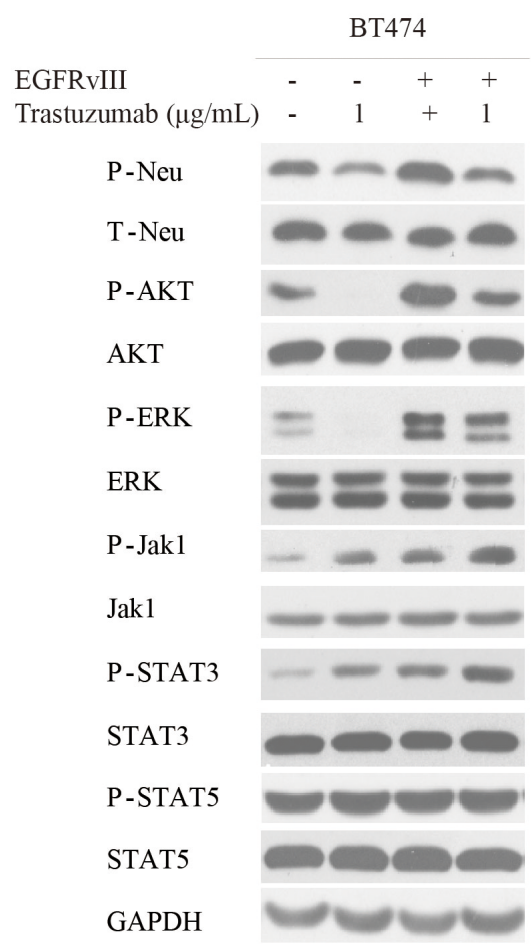

(B)

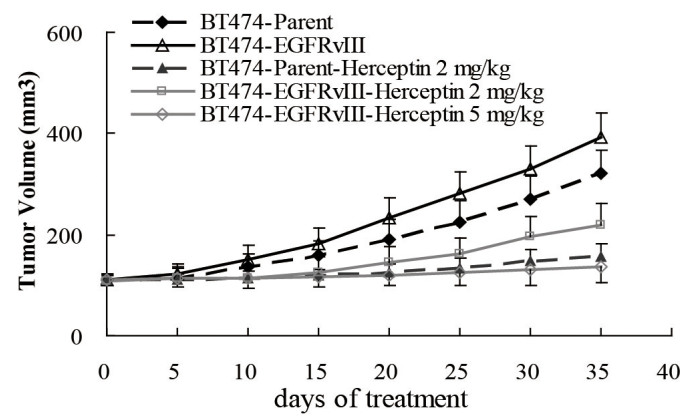

(D)

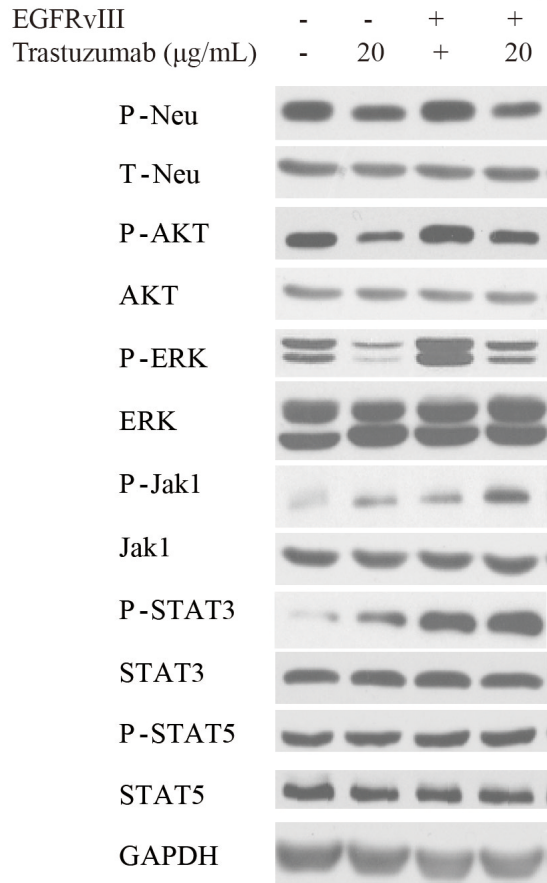

Figure 1: EGFRvIII overexpression decreased the sensitivity of breast cancers to trastuzumab. A. Cell proliferation of parental BT474 and SKBR3 cell lines and their corresponding EGFRvIII overexpression sublines upon treatment with trastuzumab at a concentration of $1 \mu \mathrm{g} / \mathrm{mL}$ for BT474 and at a concentration of $20 \mu \mathrm{g} / \mathrm{mL}$ for SKBR3. Data are expressed as the inhibition rate of cell growth in triplicate experiments (Bars, SD). Statistical significance is indicated versus parental cells $* P<0.05,{ }^{*} P<0.01, * * * P<0.001$. B. Growth curve of xenografts derived from either BT474 parental or EGFRvIII overexpression subline upon treatment with vehicle or trastuzumab at a concentration of 2 and $5 \mathrm{mg} / \mathrm{kg}$ intraperitoneally, once a week for 2 weeks. The data are expressed as mean tumor volumes \pm SE. C., D. Changes of EGFR or HER2 relevant signaling after trastuzumab treament in BT474 and BT474-EGFRvIII C. or SKBR3 and SKBR3-EGFRvIII D. cells. 
the combination of trastuzumab with $\mathrm{CH} 12$ could reverse trastuzumab resistance in EGFRvIII $^{+} \mathrm{HER}^{+}$breast cancer. First, we determined the combination effect of trastuzumab and $\mathrm{CH} 12$ in vitro. The cell viability after treated by trastuzumab, $\mathrm{CH} 12$ and the combination were $69.6 \%, 68.6 \%$, and $42.1 \%$ in BT474-EGFRvIII cells, and

(A)
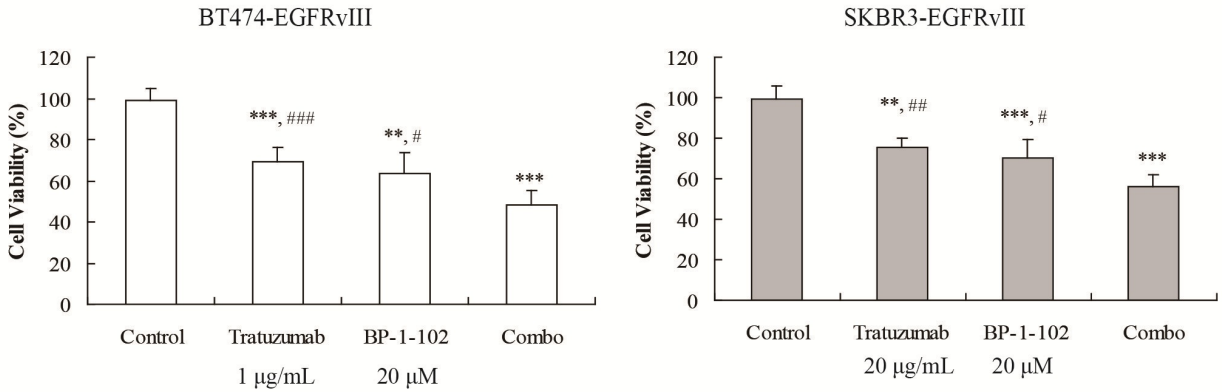

(B)

BT474-EGFRvIII

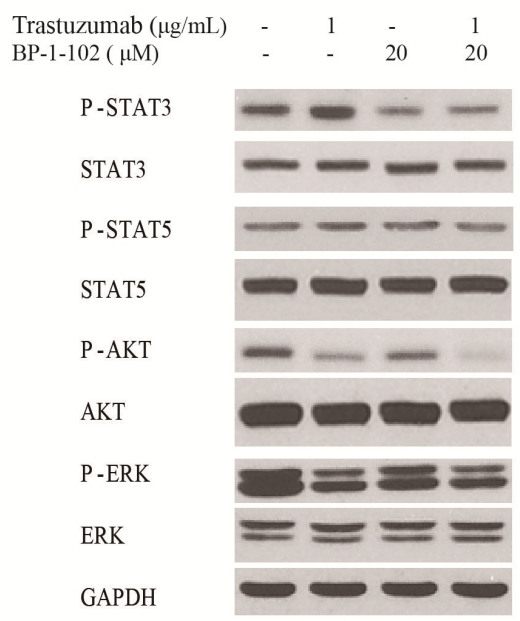

SKBR3-EGFRvIII

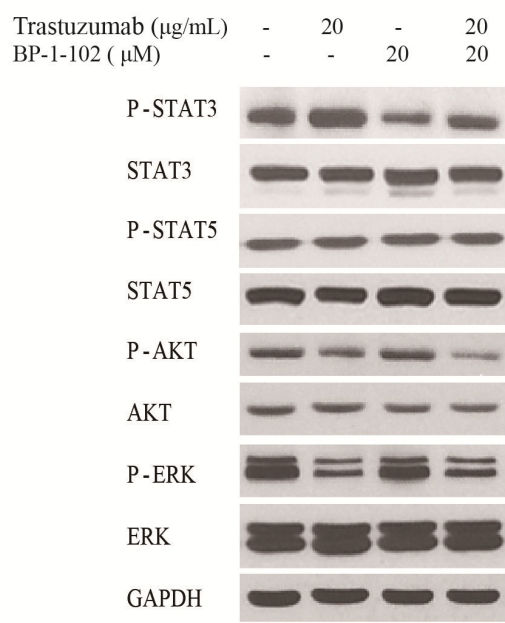

(C)
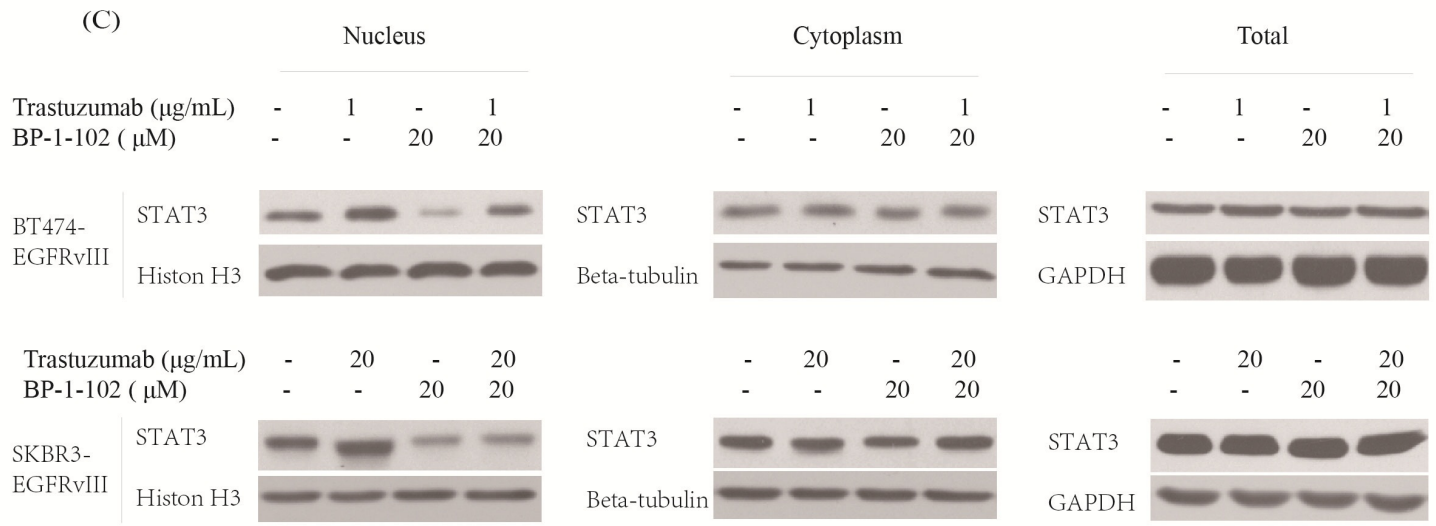

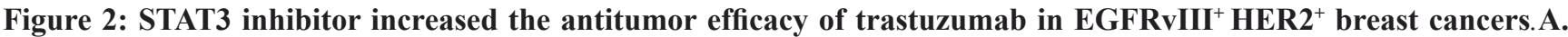
The cytotoxicities effects of STAT3 inhibitor BP-1-102 in combination with trastuzumab on BT474-EGFRvIII and SKBR3-EGFRvIII cells. BT474-EGFRvIII cells were exposed to trastuzumab at a concentration of $1 \mu \mathrm{g} / \mathrm{mL}, \mathrm{BP}-1-102$ at a concentration of $20 \mu \mathrm{M}$ or their combination for 48 hours. SKBR3-EGFRvIII cells were treated with trastuzumab at a concentration of $20 \mu \mathrm{g} / \mathrm{mL}$ or BP-1-102 at a concentration of $20 \mu \mathrm{M}$ or the combination for 48 hours. Data are expressed as the cell viability in triplicate experiments (Bars, SD). ${ }^{*} P<$ $0.05,{ }^{* *} P<0.01,{ }^{* * *} P<0.001$ versus control group, $\# P<0.05$, \#\# $P<0.01$, \#\#\# $P<0.001$ versus combo group. B. Signaling events upon treatment with BP-1-102, trastuzumab or the combination in BT474-EGFRvIII and SKBR3-EGFRvIII cells. C. Immunoblots evaluating HER2 and STAT3 nucleus translocation in BT474-EGFRvIII and SKBR3-EGFRvIII cells after BP-1-102, trastuzumab or the combination treatment. 
$72.2 \%, 75.6 \%$ and $50.5 \%$ in SKBR3-EGFRvIII cells. The results illustrated that the combination imposed a synergetic growth-inhibition effect on both BT474EGFRvIII and SKBR3-EGFRvIII cells compared with either antibody alone $(P<0.01, \mathrm{CDI}<1$ in both model, Figure $4 \mathrm{~A}$ and $4 \mathrm{~B})$. To investigate the in vivo antitumor effect of the combination of trastuzumab with $\mathrm{CH} 12$, mice bearing BT474-EGFRvIII xenografts were treated with trastuzumab, $\mathrm{CH} 12$ or the combination. All animals

(A)

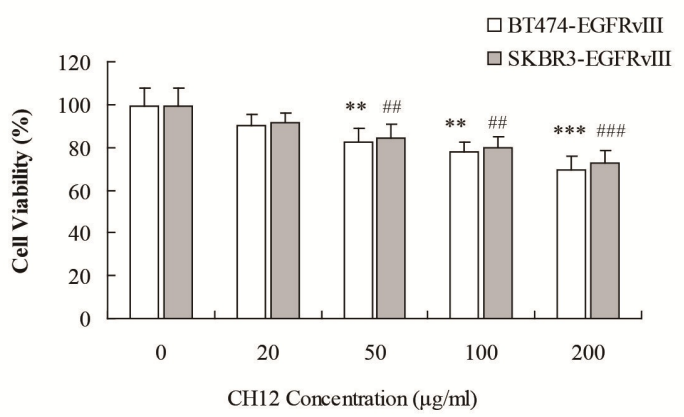

(C)

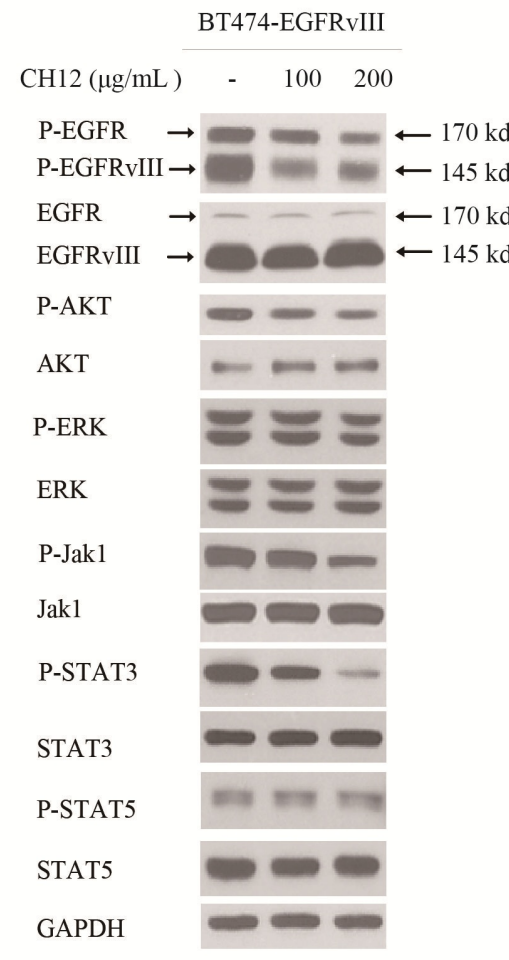

tolerated the treatments well, without observable signs of toxicity, and had stable body weights during the study. The inhibitory ratios of trastuzumab, $\mathrm{CH} 12$ and the combination on day 35 after first administration were $41 \%, 43 \%$, and 69\%, respectively (Figure 4C), which suggested that tumor growth was synergistically inhibited by the combination treatment (versus trastuzumab or CH12 treatment alone, $P<0.01, \mathrm{CDI}<1)$. Tumor weight was also measured at the end of the study (Figure 4D),

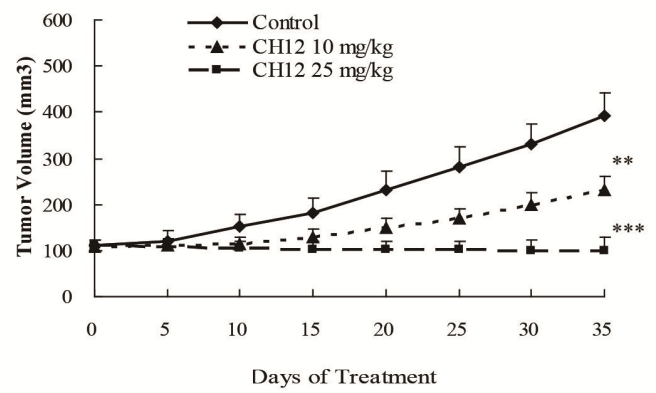

(D)

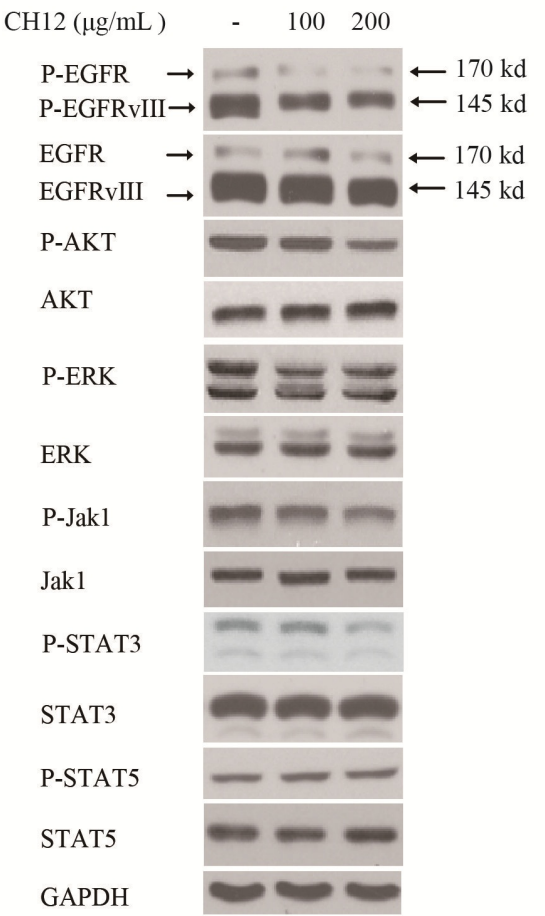

Figure 3: CH12 inhibited the growth of EGFRvIII ${ }^{+} \mathrm{HER2}^{+}$breast cancer cells in vitro and in vivo. A. The proliferation of BT474-EGFRvIII and SKBR3-EGFRvIII cells was inhibited by CH12 in a dose dependent manner. Cells were exposed to CH12 at concentrations of $20,50,100$ and $200 \mu \mathrm{g} / \mathrm{mL}$ for 48 hours and were analyzed via a CCK- 8 assay. Data are expressed as the cell viability in triplicate experiments (Bars, SD). Statistical significance is indicated versus control $* P<0.05, * * P<0.01, * * * P<0.001$ for BT474EGFRvIII cells, and \# $P<0.05$, \#\# $P<0.01$, \#\#\# $P<0.001$ for SKBR3-EGFRvIII cells. B. Growth curve of BT474-EGFRvIII xenografts treated by vehicle, $\mathrm{CH} 12$ at a concentration of $10 \mathrm{mg} / \mathrm{kg}$ or $25 \mathrm{mg} / \mathrm{kg}$, intraperitoneally, three times per week for 2 weeks. The data are expressed as mean tumor volumes \pm SE. Statistical significance is indicated versus vehicle $* P<0.05, * * P<0.01, * * * P<0.001$. C., D. The changes of relevant signaling pathway in BT474-EGFRvIII C. and SKBR3-EGFRvIII D. cells after CH12 treatment. 
and the result was consistent with that of tumor volume. Taken together, these data indicated that the combination of trastuzumab and $\mathrm{CH} 12$ exhibited synergistic antitumor activity in vitro and in vivo.

\section{Combination of trastuzumab with $\mathrm{CH} 12$ suppressed the EGFR downstream pathway and STAT3 feedback activation}

To gain further insight into the molecular events occurring in combination-treated cells, certain key signaling molecules were examined via Western blot analysis. The phosphorylation level of AKT and ERK in the combination treatment cells was lower than those in the monotherapy groups, and the phosphorylation of Jak1

(A)

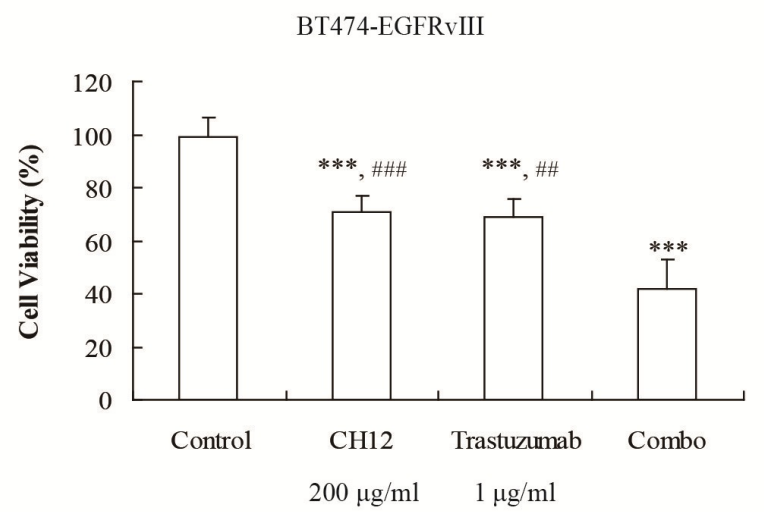

(C)

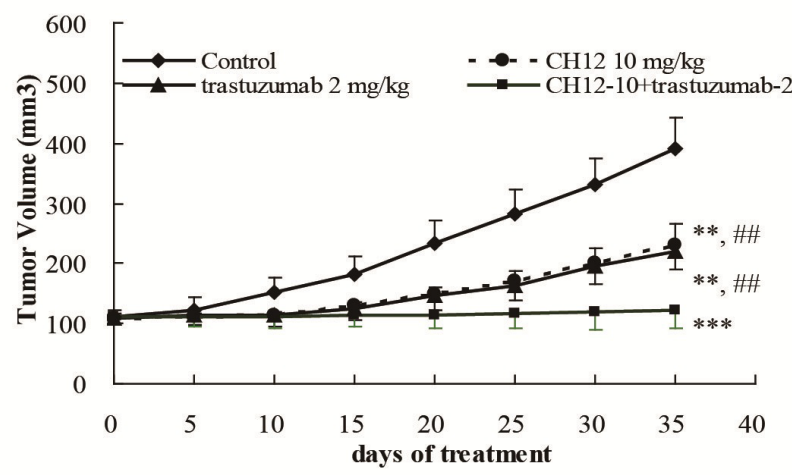

and STAT3 was also significantly inhibited compared with the trastuzumab group (Figure 5A and 5B). Similar changes of these molecules were also observed in the BT474-EGFRvIII xenograft models (Figure S3).

STAT3 need to dimerize to transmit signals to the nucleus and function as a transcription factor [32]. It was reported that the STAT3/HER2/HER3 complex could translocate to the nucleus and promote cyclinD1 translation [33], which is a vital cell cycle regulator for cell cycle progression in phase G1. Therefore, we examined the nuclear translocation of HER2 and STAT3. The results showed that combination treatment inhibited their nuclear translocation (Figure 5B and 5C) and reduced the expression of cyclin D1 (Figure 5A and 5B). Together, the combination inhibited the AKT, ERK and Jak1/ STAT3 pathways more efficiently when compared with

(B)

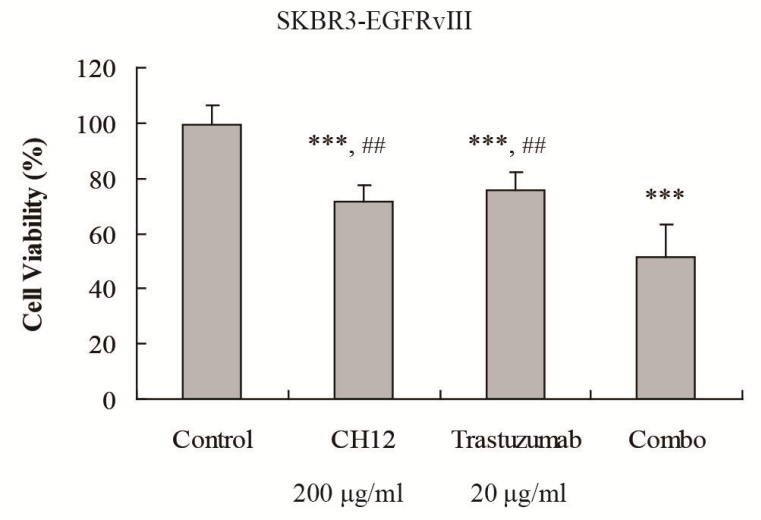

(D)

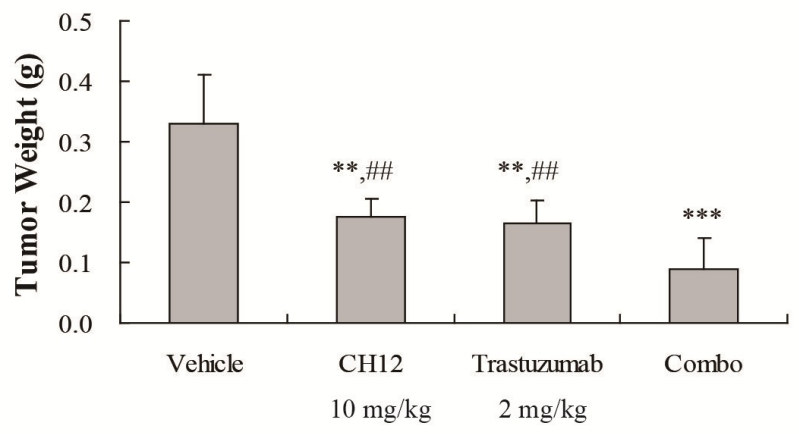

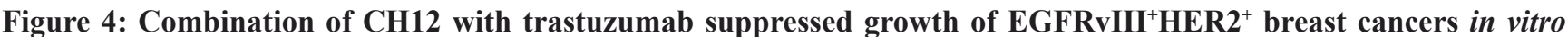
and in vivo. A., B. The efficacy of trastuzumab in combination with CH12 in BT474-EGFRvIII and SKBR3-EGFRvIII cells. A. BT474EGFRvIII cells were exposed to $\mathrm{CH} 12$ at a concentration of $200 \mu \mathrm{g} / \mathrm{mL}$, trastuzumab at a concentration of $1 \mu \mathrm{g} / \mathrm{mL}$ or the combination for 48 hours. B. SKBR3-EGFRvIII cells were treatment by CH12 at a concentration of $200 \mu \mathrm{g} / \mathrm{mL}$, trastuzumab at a concentration of $20 \mu \mathrm{g} /$ $\mathrm{mL}$ or the combination for 48 hours. Data are expressed as the cell viability in triplicate experiments (Bars, SD). C., D. Growth curve C. and tumor weight D. of BT474-EGFRvIII xenografts upon intraperitoneally treatment with vehicle, trastuzumb at a concentration of $2 \mathrm{mg} /$ $\mathrm{kg}$ weekly, $\mathrm{CH} 12$ at a concentration of $10 \mathrm{mg} / \mathrm{kg}$ three times a week or the combination for 2 weeks. Data are the mean tumor volumes \pm

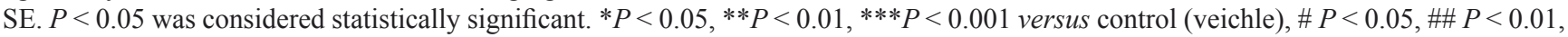
\#\#\# $P<0.001$ versus combo group. 


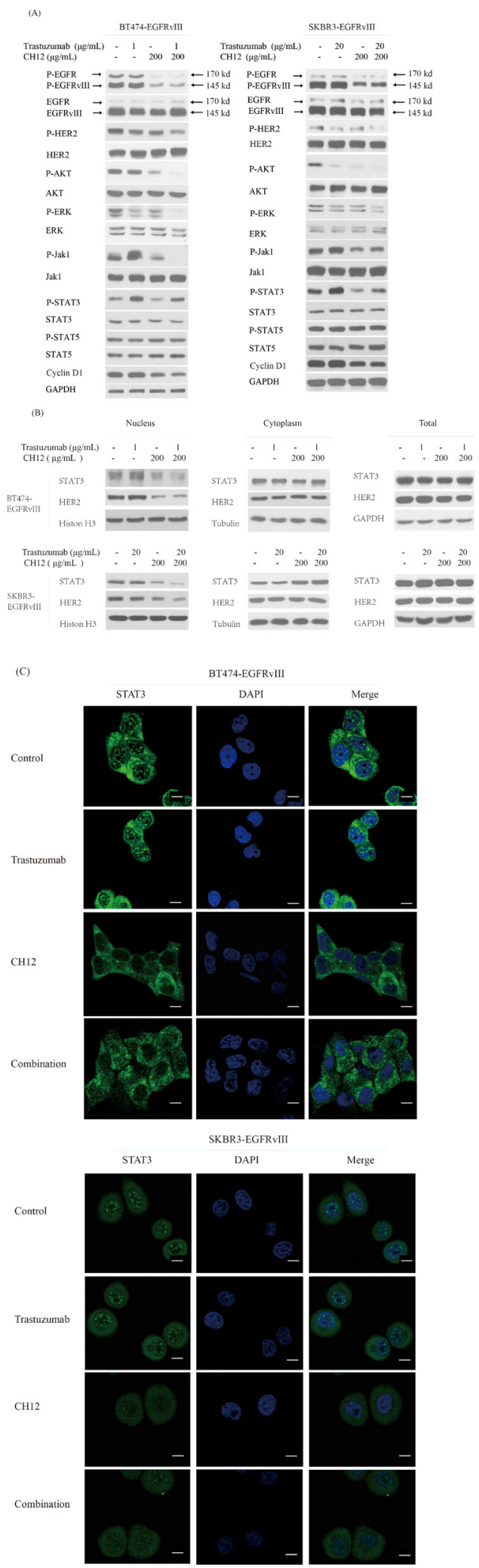

Figure 5: Combination of CH12 with trastuzumab suppressed the EGFR downstream pathway and STAT3 feedback activation. A. Signaling events in BT474-EGFRvIII and SKBR3-EGFRvIII cells upon treatment with control, CH12, trastuzumab or the combination for 48 hours. B., C. HER2 and STAT3 nucleus translocation evaluated by western blot B., or STAT3 translocation evaluated by immunofluorescence C. after BT474-EGFRvIII and SKBR3-EGFRvIII cells treatment with control, CH12, trastuzumab or the combination for 48 hours. The scale bars equal to $20 \mu \mathrm{m}$ C.. 
trastuzumab monotherapy. The combination treatment also strongly inhibited STAT3 and HER2 nuclear translocation and reduced the cyclin D1 expression.

\section{Combination of trastuzumab with $\mathrm{CH12}$ potently reduced proliferation and angiogenesis, and induced apoptosis in EGFRvIII ${ }^{+} \mathrm{HER2}^{+}$breast cancers}

To further elucidate the causes underlying the in vivo synergistic activity of trastuzumab and $\mathrm{CH} 12$, the proliferative index, tumor microvessel density as well as the apoptotic index was evaluated. The proliferative index was significantly lower in the combination-treatment group than the vehicle group as well as the monotherapy groups $(P<0.05$ monotherapy versus combination; Figure $6 \mathrm{~A}$ and $6 \mathrm{~B})$.

The number of the CD34-positive microvessels in the combination-treatment group was also significantly less than that in the monotherapy groups $(P<0.05$ monotherapy versus combination; Figure 6C and 6D). VEGF-A expression in $\mathrm{CH} 12$ and combination group abated significantly when compared with control and trastuzumab group $(P<0.05$, Figure $6 \mathrm{G})$.

TUNEL staining demonstrated a significant increase in the number of apoptotic cells in the combinationtreatment group compared with the monotherapy groups $(P<0.01$, Figure 6E and 6F). Consistently, cleaved caspase 3 and cleaved PARP increased obviously while the expression of $\mathrm{Bcl}-\mathrm{XL}$, an anti-apoptosis protein reduced significantly (Figure 6G). Together, these data showed that trastuzumab and $\mathrm{CH} 12$ combination therapy had a stronger effect on reducing tumor proliferation and angiogenesis and inducing tumor cell apoptosis than monotherapy in vivo, leading to synergistic tumor inhibition.

\section{DISCUSSION}

Although EGFRvIII has been demonstrated to coexpress with HER2 in breast cancer, its contribution to the sensitivities of breast cancer against trastuzumab has not been determined. Our study indicated that EGFRvIII expression could decrease the sensitivity of breast cancer cells against trastuzumab via activating the ERK, AKT and Jak1/STAT3 pathways (Figure 1), which suggested that EGFRvIII inhibitor might reduce trastuzumab resistance.

Intriguingly, we observed that the Jak1/STAT3 pathway was significantly activated in trastuzumabtreated EGFRvIII $^{+}$HER2 $^{+}$breast cancer cells. STAT3 is constitutively activated in many types of human cancers, including breast cancer, and plays crucial roles in regulating tumor cell proliferation, survival, invasion, and angiogenesis $[32,34]$. STAT3 activation has also been reported as a vital cause contributing to trastuzumab resistance in $\mathrm{HER}^{+}$breast and gastric cancer [35]. In approximately $50-60 \%$ of the primary breast tumors, STAT3 has been reported constitutively activated through phosphorylation by cytoplasmic non-receptor tyrosine kinases [36, 37]. Accumulating evidence has demonstrated that STAT3 activation is also associated with drug resistance as a considerable feedback loop and limits the efficacy of agents [38-40], such as various RTK inhibitors [41]. Furthermore, it was reported that STAT3/ HER2/HER3 complex translocates to the nucleus and promotes cyclinD1 translation, which is a major driver of in trastuzumab resistance [32]. In this study, we revealed that STAT3 inhibition significantly increased the antitumor effect of trastuzumab on EGFRvIII ${ }^{+} \mathrm{HER} 2^{+}$breast cancers (Figure 2), implicating that STAT3 inhibitors might be used to increase the antitumor effect of trastuzumab on EGFRvIII $^{+}$HER2 ${ }^{+}$breast cancers..

Our previous data demonstrated that mab $\mathrm{CH} 12$ could selectively bind to EGFRvIII and significantly suppress the growth of EGFRvIII-positive tumor xenografts [26]. Here we demonstrated that $\mathrm{CH} 12$ had a significant growth-suppression effect on EGFRvIII ${ }^{+} \mathrm{HER}^{+}$ breast cancers in vitro and in vivo (Figure $3 \mathrm{~A}$ and $3 \mathrm{~B}$ ) at least partially through inhibiting the phosphorylation of EGFR, AKT and STAT3 (Figure 3C and 3D). Thus, it seems rational to combine $\mathrm{CH} 12$ and trastuzumab, which have opposite role on STAT3 phosphorylation.

As we expected, CH12 in combination with trastuzumab exhibited synergistic antitumor activity in EGFRvIII ${ }^{+} \mathrm{HER}^{+}$breast cancers in vitro and in vivo (Figure 4). The combination inhibited the ERK or AKT pathway more efficiently and abrogated the feedback activation of STAT3 caused by trastuzumab treatment. Additionally, the combination lessened the nuclear translocation of STAT3 and HER2 and reduced cyclin D1 expression, leading to increased efficacy (Figure 5). Furthermore, compared with the monotherapy, the combination treatment significantly suppressed tumor proliferation and microvessel density while significantly induced apoptosis (Figure 6). It has been reported that STAT3 phosphorylation promotes angiogenesis various cancer types including breast cancer and the expression of angiogenic factor VEGF-A plays a vital role in STAT3induced angiogenesis [42-44]. In this study, VEGF-A expression and the microvessel density in the combination group reduced significantly than trastuzumab monotherapy group (Figure 6C, 6D and 6G), indicating that antiangiogenesis played important role in the antitumor activities of the combination treatment.

It is well known that the toxic side effects on normal tissue present huge obstacles in cancer treatment and lead to dose reductions, treatment delays, and even the discontinuation of therapy. In this study, we demonstrated that STAT3 inhibitor could increase the antitumor activities of trastuzumab. However, STAT3 inhibitor could not distinguish the STAT3 in normal cells and cancer cells and might cause severe side effects. 

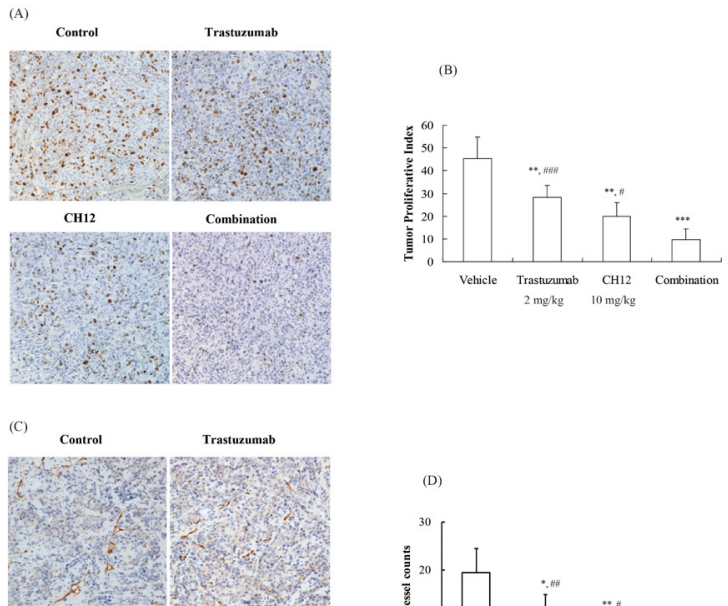

CH12

Combination
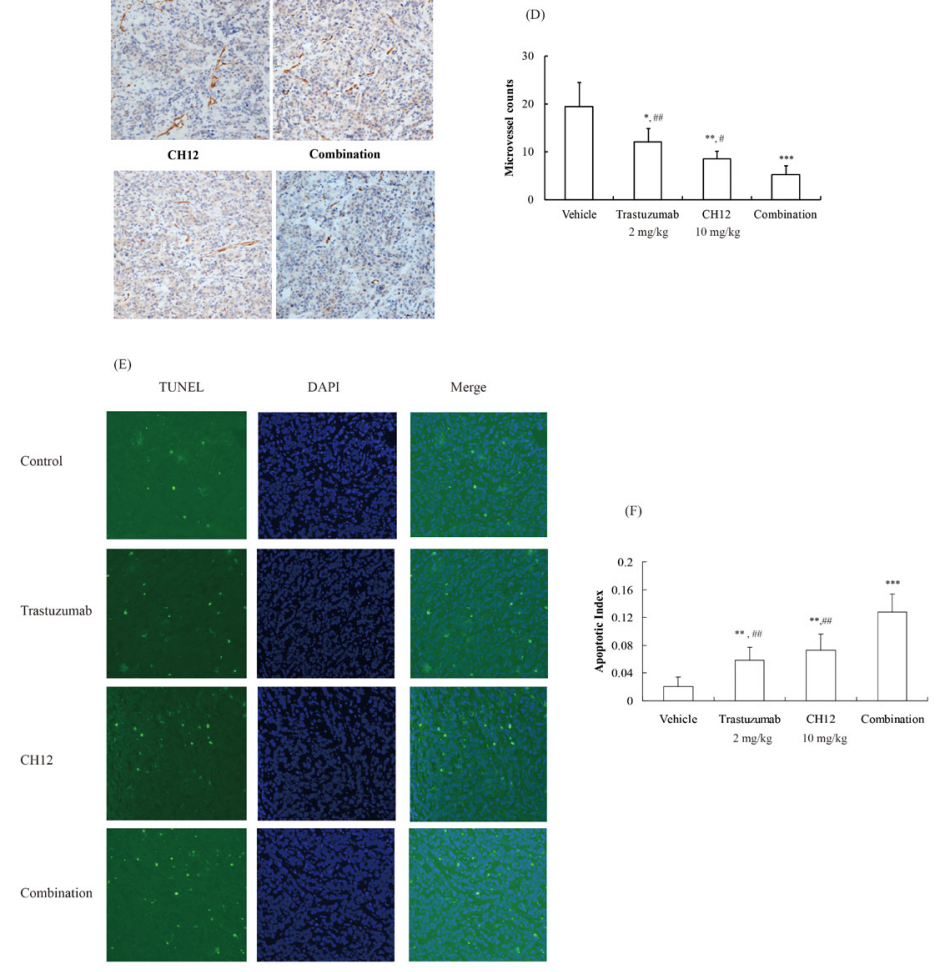

(G)

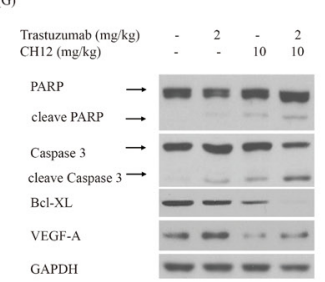

Figure 6: Combination of $\mathrm{CH12}$ with trastuzumab reduced proliferation and angiogenesis and induced apoptosis in the tumor xenografts. A. Trastuzumab combination with $\mathrm{CH} 12$ treatment led to less growth compared with other treatments in BT474EGFRvIII xenograft. Tumor sections were stained for Ki-67. The cell proliferative index was assessed as the percentage of total cells that were Ki-67 positive from six randomly selected high power fields $(\times 200)$ in xenografts from six mice of each group. B. The quantitative analysis of Ki-67 staining. C. Trastuzumab combination with CH12 treatment led to less vascularization compared with control in BT474EGFRvIII xenograft. Tumor sections were immunostained with anti-CD34 antibody. MVD values were analyzed by measuring the number of stained microvessels from six randomly selected fields $(\times 200)$ in xenografts from six mice of each group. D. The quantitative analysis of CD34 staining. E. Combination treatment led to an increase in apoptosis compared with control in BT474-EGFRvIII xenografts. Apoptotic cells were detected using the TUNEL assay. The apoptotic index was assessed by the ratio of TUNEL-positive cells : total number of cells from six randomly selected high power fields $(\times 200)$ in xenografts from six mice of each group. F. The quantitative analysis of TUNEL assay. G. Signaling events related to apoptosis and angiogenesis upon treatment with $\mathrm{CH} 12$, trastuzumab or the combination in BT474EGFRvIII xenograft. Data are the mean $\pm \mathrm{SD} .{ }^{*} P<0.05,{ }^{*} P<0.01,{ }^{*} * P<0.001$ versus veichle, $\# P<0.05$, \#\# $P<0.01$, \#\#\# $P<0.001$ versus combo group. 
In contrast, $\mathrm{CH} 12$ targets a cryptic epitope of EGFR or EGFRvIII, which only exposes in tumor cells and not in normal tissue, leading to a good safety profile. Clinically, mab 806, which targets a similar epitope as $\mathrm{CH} 12$, was well tolerated at all dose levels with generally predictable and manageable minor toxicities being observed [45]. Thus, the combination of trastuzumab with $\mathrm{CH} 12$ might show a larger safety window when compared with the combination of trastuzumab with JAK1/STAT3 inhibitors.

In summary, EGFRvIII expression increased the de novo resistance of breast cancer cells against trastuzumab, and the feedback activation of STAT3 caused by trastuzumab also contributed to acquired resistance in EGFRvIII ${ }^{+} \mathrm{HER} 2^{+}$breast cancers. Moreover, the combination of trastuzumab and $\mathrm{CH} 12$ could synergistically inhibit the growth of EGFRvIII HER2 ${ }^{+}$ breast cancer via attenuating phosphorylation ERK and AKT more effectively and reversing STAT3 feedback activation. Taken together, we propose that the combination of Trastuzumab and CH12 might be a novel treatment strategy for the patients with EGFRvIII HER2 ${ }^{+}$ breast cancer.

\section{MATERIALS AND METHODS}

\section{Cell culture}

The human breast cancer cells BT474 (HER2/ERpositive) and SKBR3 (HER2-positive/ER-negative) were obtained from American Type Culture Collection. BT474 and SKBR3 with exogenous EGFRvIII overexpression were established according to previously reported methods [27]. All breast cancer cells were cultured in 1640 medium (Gibco, USA) supplemented with 10\% fetal bovine serum (Serana, Australia) and maintained at $37^{\circ} \mathrm{C}$ in a humidified atmosphere of $5 \% \mathrm{CO}_{2}$.

\section{Reagents}

Trastuzumab was purchased from Genentech, USA and dissolved in PBS buffer at a concentration of $22 \mathrm{mg} /$ $\mathrm{mL}$. The chimeric mAb CH12 (IgG1) was produced in dihydrofolate reductase-deficient $\mathrm{CHO}$ DG44 cells as described previously at $20 \mathrm{mg} / \mathrm{mL}$ [26].

\section{FACS analysis}

$1 \times 10^{6}$ cells were collected by centrifugation and incubated with $20 \mu \mathrm{g} / \mathrm{mL}$ primary antibody, in phosphatebuffered saline containing $1 \%$ newborn calf serum for $45 \mathrm{~min}$ at $4^{\circ} \mathrm{C}$. After being washed with cold phosphatebuffered saline, cells were incubated for an additional 45 min at $4^{\circ} \mathrm{C}$ with an FITC-conjugated goat anti-human antibody (Kang-Chen Bio-tech, Shanghai, China) in the dark. For each sample, at least 10,000 cells were analyzed by FACS cytometry (Beckman Coulter Epics Altra, Miami, FL).

\section{RNA interference assay}

\section{STAT3}

siRNA (5'-AGUCAGGUUGCUGGUCAAA-3') and negative control siRNA (siN05815122147) were purchased from Ribobio, Guangzhou, China [28]. The cells were plated at $50 \%$ confluence, transfected with $50 \mathrm{nM}$ siRNA overnight in Opti-MEM containing Lipofectamine 2000 (Invitrogen), and incubated for various amounts of time.

\section{In vitro cell proliferation assay}

The cells were seeded in 96-well plates at a density of 5000 cells per well. After 24 hours, the cell media was replaced with media containing trastuzumab or $\mathrm{CH} 12$ at different concentrations or PBS (vehicle), using five wells per concentration. After 48 hours, cell proliferation was measured using a CCK-8 kit (Dojindo Laboratories, Rockville, MD). CCK-8 solution (10 $\mu$ l) was added to 90 $\mu \mathrm{l}$ of culture media and incubated for $1 \mathrm{~h}$ at $37^{\circ} \mathrm{C}$ in a humidified atmosphere of $5 \% \mathrm{CO}_{2}$. The optical density was measured at $450 \mathrm{~nm}$ in a microplate reader. The experiment was performed in triplicate at different times.

\section{Western blotting analysis}

Protein lysates were obtained from BT474EGFRvIII and SKBR3-EGFRvIII cells using a lysis buffer (Prod\# 78501, Thermo, USA) with a protease inhibitor cocktail. Cell lysates were collected after centrifugation at $12,000 \mathrm{~g}$ for 10 minutes at $4^{\circ} \mathrm{C}$. The tumor tissues were surgically excised and frozen in liquid nitrogen and then homogenized in tumor lysis buffer (Prod\# 78510, Thermo, USA); after centrifugation at $12,000 \mathrm{~g}$ for 10 minutes at $4^{\circ} \mathrm{C}$, the lysates were collected. The protein was quantified using a BCA Kit (Prod\# 23225, Thermo, USA), separated on SDS-PAGE gels at $8 \%-14 \%$ polyacrylamide according to protein weight and blotted onto a PVDF nitrocellulose membrane (Bio-Rad Laboratories, USA). The membrane was blocked in 5\% milk in PBST for 1 hour and then probed with primary antibodies overnight at $4^{\circ} \mathrm{C}$. The following primary antibodies were used: the phosphorHER2, HER2, phosphor-EGFR, EGFR, phosphor-ERK, ERK, Bcl-xL, and p27 antibodies purchased from Santa Cruz Biotechnology, and the cleaved caspase3, caspase3, PARP, phosphor-Akt (Ser473), Akt, Jak1, phosphorJak1, STAT5, phosphor-STAT5, STAT3 and phosphorSTAT3 (Tyr705) antibodies obtained from Cell Signaling Technology. After the membranes were washed in PBST 
and incubated with the appropriate secondary antibodies for $1 \mathrm{~h}$ at room temperature, washed three times in PBST and then visualized with enhanced chemiluminescence reagent, following the manufacturer's instructions (Prod\# 34080, Thermo, USA).

\section{Tumor xenograft studies}

All mouse experiments were performed in accordance with approved protocols from Shanghai Medical Experimental Animal Care Commission. BT474EGFRvIII cells $\left(1 \times 10^{\wedge} 7\right)$ in $100 \mu$ of 1640 -Matrigel mixture (1:1 ratio) were injected subcutaneously in the right lateral flank of 6-week-old nude mice. When the tumor volumes reached an average of approximately $100 \mathrm{~mm}^{3}$, we treated the mice with vehicle control (three times per week), trastuzumab (once per week), CH12 (three times per week) or trastuzumab-CH12 combination intraperitoneally. Tumor volumes were measured every five days in two dimensions with vernier calipers. The tumor volumes were calculated using the following formula: length $\times$ width $^{2} \times 0.5$. Two weeks after the final treatment, the mice were sacrificed and the tumors were surgically excised and weighed. Tumor tissues from the in vivo experiments were collected for Western blot analysis and immunohistochemical studies.

\section{Immunohistochemical (IHC) analysis}

To assess angiogenesis and cell proliferation in tumors, formalin-fixed paraffin-embedded tumor tissues were immunostained using monoclonal antibodies antiCD34 (Abcam, Cambridge, UK) and anti-Ki-67 (Santa Cruz Biotechnology, USA). After deparaffinization and rehydration, the tissue sections were incubated with 3\% hydrogen peroxide in methanol to quench endogenous peroxidase. The sections were blocked for 30 minutes with $1 \% \mathrm{BSA}$ and incubated with the primary antibodies at $4{ }^{\circ} \mathrm{C}$ overnight. As negative controls, staining was performed in the absence of the primary antibodies. The sections were then washed with PBS and incubated with HRP-conjugated secondary antibodies for one hour. The products were then visualized using a diaminobenzidine staining kit (TIANGEN Biotech, Beijing, China) and counterstained in hematoxylin.

As a measure of proliferation, the Ki-67 labeling index was determined as the ratio of (labeled nuclei) / (total nuclei) in high power fields $(\times 200)$. Approximately 2000 nuclei were counted in each case by systematic random sampling.

Microvessel density (MVD) was determined by measuring the number of stained microvessels in each section from six mice of each group as described [29]. The mean microvessel count of the six most vascular areas was taken as the MVD, which was expressed as the absolute number of microvessels per $0.74 \mathrm{~mm}^{2}$ ( $\times 200$ field).

\section{TUNEL assay}

The TUNEL assay was performed according to kit instructions (Qia39, Merck, USA). The tumor tissues sections were deparaffinized, rehydrated and incubated with proteinase $\mathrm{K}(20 \mu \mathrm{g} / \mathrm{mL})$ for 20 minutes at $37^{\circ} \mathrm{C}$. After several washes with TBS, the specimen was covered in $1 \times$ equilibration buffer for 30 minutes, and the incubated with a mixture of $57.0 \mu \mathrm{l}$ of Fluorescein-FragEL ${ }^{\mathrm{TM}} \mathrm{TdT}$ Labeling Reaction Mix and $3 \mu \mathrm{l}$ of TdT Enzyme for 1.5 hours at $37^{\circ} \mathrm{C}$ in the dark. Then, the slides were rinsed in TBS three times. A glass coverslips were mounted using Fluorescein-FragEL ${ }^{\mathrm{TM}}$ Mounting Media and slides were visualized under a fluorescence microscope (OLYMPUS IX71, Japan). TUNEL-positive cells were counted at $\times 400$ magnification. The apoptotic index was calculated as a ratio of (apoptotic cell number) / (total cell number) in each field.

\section{Evaluation of the combination effect}

The coefficient of drug interaction (CDI) was used to evaluate the combination effect. $\mathrm{CDI}$ is calculated in in vitro $\mathrm{CCK}-8$ assay as follows: $\mathrm{CDI}=\mathrm{AB} /(\mathrm{A} \times \mathrm{B}) . \mathrm{AB}$ is the cell viability of combination group and $\mathrm{A}$ or $\mathrm{B}$ is the cell viability of antibody monotherapy group. In in vivo tumor xenograft model, end point tumor sizes were analyzed for combination effect using the formula $\mathrm{CDI}=$ $(\mathrm{AB} / \mathrm{C}) /(\mathrm{A} / \mathrm{C} \times \mathrm{B} / \mathrm{C})$, where $\mathrm{C}$ is the tumor volume of the vehicle group, $\mathrm{A}$ or $\mathrm{B}$ is the tumor volume of antibody monotherapy group, and $\mathrm{AB}$ is the tumor volume of the combination group. CDI value $<1,=1$ or $>1$ indicates that the combination is synergistic, additive or antagonistic, respectively $[30,31]$.

\section{Statistical analysis}

All data are presented as the mean $\pm \mathrm{SE}$ or mean \pm SD. Statistical significance was determined by paired or unpaired Student $t$ test in cases of standardized expression data. One-way ANOVA was performed for multiple group comparisons and comparisons between two groups were conducted using the least significant difference method. $P$ $<0.05$ was considered significant.

\section{FINANCIAL SUPPORT}

The study was funded by the Supporting Programs of the "Twelfth Five-year Plan" for Science \& Technology Research of China (2012ZX09103-301005), and the National Natural Science Foundation (Grant No. 81272539 and 81372468), Shanghai Science and 
Technology Development Funds (Grant No. 12JC1408300 and 14431903500), and Shanghai Rising-Star Program (A type; 13QA1403300).

\section{CONFLICTS OF INTEREST}

All authors declare no conflicts of interest.

\section{REFERENCES}

1. Menard S, Casalini P, Campiglio M, Pupa S, Agresti R, Tagliabue E. HER2 overexpression in various tumor types, focussing on its relationship to the development of invasive breast cancer. Ann Oncol. 2001; 12 Suppl 1: S15-S19.

2. Press MF, Bernstein L, Thomas PA, Meisner LF, Zhou JY, Ma Y, Hung G, Robinson RA, Harris C, El-Naggar A, Slamon DJ, Phillips RN, Ross JS, Wolman SR, Flom KJ. HER-2/neu gene amplification characterized by fluorescence in situ hybridization: poor prognosis in nodenegative breast carcinomas. J Clin Oncol. 1997; 15: 28942904.

3. Gianni L, Dafni U, Gelber RD, Azambuja E, Muehlbauer S, Goldhirsch A, Untch M, Smith I, Baselga J, Jackisch C, Cameron D, Mano M, Pedrini JL, Veronesi A, Mendiola C, Pluzanska A, Semiglazov V, Vrdoljak E, Eckart MJ, Shen Z, Skiadopoulos G, Procter M, Pritchard KI, PiccartGebhart MJ, Bell R. Treatment with trastuzumab for 1 year after adjuvant chemotherapy in patients with HER2-positive early breast cancer: a 4-year follow-up of a randomised controlled trial. Lancet Oncol. 2011; 12: 236-244.

4. Marty M, Cognetti F, Maraninchi D, Snyder R, Mauriac L, Tubiana-Hulin M, Chan S, Grimes D, Anton A, Lluch A, Kennedy J, O’Byrne K, Conte P, Green M, Ward C, Mayne K, Extra JM. Randomized phase II trial of the efficacy and safety of trastuzumab combined with docetaxel in patients with human epidermal growth factor receptor 2-positive metastatic breast cancer administered as first-line treatment: the M77001 study group. J Clin Oncol. 2005; 23: 42654274.

5. Slamon DJ, Leyland-Jones B, Shak S, Fuchs H, Paton V, Bajamonde A, Fleming T, Eiermann W, Wolter J, Pegram M, Baselga J, Norton L. Use of chemotherapy plus a monoclonal antibody against HER2 for metastatic breast cancer that overexpresses HER2. N Engl J Med. 2001; 344: 783-792.

6. Romond EH, Perez EA, Bryant J, Suman VJ, Geyer CJ, Davidson NE, Tan-Chiu E, Martino S, Paik S, Kaufman PA, Swain SM, Pisansky TM, Fehrenbacher L, Kutteh LA, Vogel VG, Visscher DW, Yothers G, Jenkins RB, Brown AM, Dakhil SR, Mamounas EP, Lingle WL, Klein PM, Ingle JN, Wolmark N. Trastuzumab plus adjuvant chemotherapy for operable HER2-positive breast cancer. N Engl J Med. 2005; 353: 1673-1684.

7. Vogel CL, Cobleigh MA, Tripathy D, Gutheil JC, Harris LN, Fehrenbacher L, Slamon DJ, Murphy M, Novotny WF,
Burchmore M, Shak S, Stewart SJ, Press M. Efficacy and safety of trastuzumab as a single agent in first-line treatment of HER2-overexpressing metastatic breast cancer. J Clin Oncol. 2002; 20: 719-726.

8. Seidman AD, Berry D, Cirrincione C, Harris L, Muss H, Marcom PK, Gipson G, Burstein H, Lake D, Shapiro CL, Ungaro P, Norton L, Winer E, Hudis C. Randomized phase III trial of weekly compared with every-3-weeks paclitaxel for metastatic breast cancer, with trastuzumab for all HER-2 overexpressors and random assignment to trastuzumab or not in HER-2 nonoverexpressors: final results of Cancer and Leukemia Group B protocol 9840. J Clin Oncol. 2008; 26: 1642-1649.

9. Nahta R, Esteva FJ. HER2 therapy: molecular mechanisms of trastuzumab resistance. Breast Cancer Res. 2006; 8: 215.

10. Piccart M. Circumventing de novo and acquired resistance to trastuzumab: new hope for the care of ErbB2-positive breast cancer. Clin Breast Cancer. 2008; 8 Suppl 3: S100-S113.

11. Berns K, Horlings HM, Hennessy BT, Madiredjo M, Hijmans EM, Beelen K, Linn SC, Gonzalez-Angulo AM, Stemke-Hale K, Hauptmann M, Beijersbergen RL, Mills GB, van de Vijver MJ, Bernards R. A functional genetic approach identifies the PI3K pathway as a major determinant of trastuzumab resistance in breast cancer. Cancer Cell. 2007; 12: 395-402.

12. Nagata Y, Lan KH, Zhou X, Tan M, Esteva FJ, Sahin AA, Klos KS, Li P, Monia BP, Nguyen NT, Hortobagyi GN, Hung MC, Yu D. PTEN activation contributes to tumor inhibition by trastuzumab, and loss of PTEN predicts trastuzumab resistance in patients. Cancer Cell. 2004; 6: 117-127.

13. Scaltriti M, Rojo F, Ocana A, Anido J, Guzman M, Cortes J, Di Cosimo S, Matias-Guiu X, Ramon YCS, Arribas J, Baselga J. Expression of p95HER2, a truncated form of the HER2 receptor, and response to anti-HER2 therapies in breast cancer. J Natl Cancer Inst. 2007; 99: 628-638.

14. Lu Y, Zi X, Zhao Y, Mascarenhas D, Pollak M. Insulinlike growth factor-I receptor signaling and resistance to trastuzumab (Herceptin). J Natl Cancer Inst. 2001; 93: 1852-1857.

15. Ritter CA, Perez-Torres M, Rinehart C, Guix M, Dugger T, Engelman JA, Arteaga CL. Human breast cancer cells selected for resistance to trastuzumab in vivo overexpress epidermal growth factor receptor and ErbB ligands and remain dependent on the ErbB receptor network. Clin Cancer Res. 2007; 13: 4909-4919.

16. Dua R, Zhang J, Nhonthachit P, Penuel E, Petropoulos C, Parry G. EGFR over-expression and activation in high HER2, ER negative breast cancer cell line induces trastuzumab resistance. Breast Cancer Res Treat. 2010; 122: 685-697.

17. Nahta R, Yuan LX, Zhang B, Kobayashi R, Esteva FJ. Insulin-like growth factor-I receptor/human epidermal growth factor receptor 2 heterodimerization contributes to 
trastuzumab resistance of breast cancer cells. Cancer Res. 2005; 65: 11118-11128.

18. Nishikawa R, Ji XD, Harmon RC, Lazar CS, Gill GN, Cavenee WK, Huang HJ. A mutant epidermal growth factor receptor common in human glioma confers enhanced tumorigenicity. Proc Natl Acad Sci U S A. 1994; 91: $7727-$ 7731.

19. Fernandes H, Cohen S, Bishayee S. Glycosylation-induced conformational modification positively regulates receptorreceptor association: a study with an aberrant epidermal growth factor receptor (EGFRvIII/DeltaEGFR) expressed in cancer cells. J Biol Chem. 2001; 276: 5375-5383.

20. Fernandes H, Cohen S, Bishayee S. Glycosylation-induced conformational modification positively regulates receptorreceptor association: a study with an aberrant epidermal growth factor receptor (EGFRvIII/DeltaEGFR) expressed in cancer cells. J Biol Chem. 2001; 276: 5375-5383.

21. Del VC, Jensen KC, Nitta RT, Shain AH, Giacomini CP, Wong AJ. Epidermal growth factor receptor variant III contributes to cancer stem cell phenotypes in invasive breast carcinoma. Cancer Res. 2012; 72: 2657-2671.

22. Yu H, Gong X, Luo X, Han W, Hong G, Singh B, Tang CK. Co-expression of EGFRvIII with ErbB-2 enhances tumorigenesis: EGFRvIII mediated constitutively activated and sustained signaling pathways, whereas EGF-induced a transient effect on EGFR-mediated signaling pathways. Cancer Biol Ther. 2008; 7: 1818-1828.

23. Luo X, Gong X, Tang CK. Suppression of EGFRvIIImediated proliferation and tumorigenesis of breast cancer cells by ribozyme. Int J Cancer. 2003; 104: 716-721.

24. Rahimi M, Toth TA, Tang CK. CXCR4 suppression attenuates EGFRvIII-mediated invasion and induces p38 MAPK-dependent protein trafficking and degradation of EGFRvIII in breast cancer cells. Cancer Lett. 2011; 306: 43-51.

25. Scott AM, Lee FT, Tebbutt N, Herbertson R, Gill SS, Liu Z, Skrinos E, Murone C, Saunder TH, Chappell B, Papenfuss AT, Poon AM, Hopkins W, Smyth FE, MacGregor D, Cher LM, Jungbluth AA, Ritter G, Brechbiel MW, Murphy R, Burgess AW, Hoffman EW, Johns TG, Old LJ. A phase I clinical trial with monoclonal antibody ch806 targeting transitional state and mutant epidermal growth factor receptors. Proc Natl Acad Sci U S A. 2007; 104: 40714076.

26. Jiang H, Wang H, Tan Z, Hu S, Wang H, Shi B, Yang L, Li P, Gu J, Wang H, Li Z. Growth suppression of human hepatocellular carcinoma xenografts by a monoclonal antibody $\mathrm{CH} 12$ directed to epidermal growth factor receptor variant III. J Biol Chem. 2011; 286: 5913-5920.

27. Wang H, Jiang H, Zhou M, Xu Z, Liu S, Shi B, Yao X, Yao M, Gu J, Li Z. Epidermal growth factor receptor vIII enhances tumorigenicity and resistance to 5-fluorouracil in human hepatocellular carcinoma. Cancer Lett. 2009; 279: 30-38.
28. Zhou M, Wang H, Zhou K, Luo X, Pan X, Shi B, Jiang H, Zhang J, Li K, Wang HM, Gao H, Lu S, Yao M, Mao Y, Wang HY, Yang S, Gu J, Li C, Li Z. A novel EGFR isoform confers increased invasiveness to cancer cells. Cancer Res. 2013; 73: 7056-7067.

29. Poon RT, Ng IO, Lau C, Yu WC, Yang ZF, Fan ST, Wong J. Tumor microvessel density as a predictor of recurrence after resection of hepatocellular carcinoma: a prospective study. J Clin Oncol. 2002; 20: 1775-1785.

30. Cao SS, Zhen YS. Potentiation of antimetabolite antitumor activity in vivo by dipyridamole and amphotericin B. Cancer Chemother Pharmacol. 1989; 24: 181-186.

31. Clarke R. Issues in experimental design and endpoint analysis in the study of experimental cytotoxic agents in vivo in breast cancer and other models. Breast Cancer Res Treat. 1997; 46: 255-278.

32. Yu H, Pardoll D, Jove R. STATs in cancer inflammation and immunity: a leading role for STAT3. Nat Rev Cancer. 2009; 9: 798-809.

33. Cordo RR, Beguelin W, Diaz FM, Proietti CJ, Venturutti L, Galigniana N, Tkach M, Guzman P, Roa JC, O’Brien NA, Charreau EH, Schillaci R, Elizalde PV. Targeting ErbB2 nuclear localization and function inhibits breast cancer growth and overcomes trastuzumab resistance. Oncogene. 2015; 34: 3413-3428.

34. Marotta LL, Almendro V, Marusyk A, Shipitsin M, Schemme J, Walker SR, Bloushtain-Qimron N, Kim JJ, Choudhury SA, Maruyama R, Wu Z, Gonen M, Mulvey LA, Bessarabova MO, Huh SJ, Silver SJ, Kim SY, Park SY, Lee HE, Anderson KS, Richardson AL, Nikolskaya T, Nikolsky Y, Liu XS, Root DE, Hahn WC, Frank DA, Polyak K. The JAK2/STAT3 signaling pathway is required for growth of CD44(+)CD24(-) stem cell-like breast cancer cells in human tumors. J Clin Invest. 2011; 121: 2723-2735.

35. Li G, Zhao L, Li W, Fan K, Qian W, Hou S, Wang H, Dai J, Wei H, Guo Y. Feedback activation of STAT3 mediates trastuzumab resistance via upregulation of MUC1 and MUC4 expression. Oncotarget. 2014; 5: 8317-8329.

36. Armanious H, Gelebart P, Mackey J, Ma Y, Lai R. STAT3 upregulates the protein expression and transcriptional activity of beta-catenin in breast cancer. Int J Clin Exp Pathol. 2010; 3: 654-664.

37. Yang Z, Cai JH, Xie SJ, Li GX, Song WQ, Yan QH, Yan L, Zhang F. Therapeutic effects of signal transducer and activator of transcription 3 siRNA on human breast cancer in xenograft mice. Chin Med J (Engl). 2011; 124: 18541861.

38. Chung SS, Giehl N, Wu Y, Vadgama JV. STAT3 activation in HER2-overexpressing breast cancer promotes epithelialmesenchymal transition and cancer stem cell traits. Int $\mathbf{J}$ Oncol. 2014; 44: 403-411.

39. Korkaya H, Kim GI, Davis A, Malik F, Henry NL, Ithimakin S, Quraishi AA, Tawakkol N, D'Angelo R, Paulson AK, Chung S, Luther T, Paholak HJ, Liu S, Hassan 
KA, Zen Q, Clouthier SG, Wicha MS. Activation of an IL6 inflammatory loop mediates trastuzumab resistance in HER2+ breast cancer by expanding the cancer stem cell population. Mol Cell. 2012; 47: 570-584.

40. Huang S, Chen M, Shen Y, Shen W, Guo H, Gao Q, Zou $\mathrm{X}$. Inhibition of activated Stat 3 reverses drug resistance to chemotherapeutic agents in gastric cancer cells. Cancer Lett. 2012; 315: 198-205.

41. Lee HJ, Zhuang G, Cao Y, Du P, Kim HJ, Settleman J. Drug resistance via feedback activation of Stat3 in oncogeneaddicted cancer cells. Cancer Cell. 2014; 26: 207-221.

42. Zhang X, Tang J, Zhi X, Xie K, Wang W, Li Z, Zhu Y, Yang L, Xu H, Xu Z. miR-874 functions as a tumor suppressor by inhibiting angiogenesis through STAT3/ VEGF-A pathway in gastric cancer. Oncotarget. 2015; 6: 1605-1617.

43. Kang SH, Yu MO, Park KJ, Chi SG, Park DH, Chung YG. Activated STAT3 regulates hypoxia-induced angiogenesis and cell migration in human glioblastoma. Neurosurgery. 2010; 67: 1386-1395, 1395.

44. Lee HT, Xue J, Chou PC, Zhou A, Yang P, Conrad CA, Aldape KD, Priebe W, Patterson C, Sawaya R, Xie K, Huang S. Stat3 orchestrates interaction between endothelial and tumor cells and inhibition of Stat 3 suppresses brain metastasis of breast cancer cells. Oncotarget. 2015; 6: 10016-10029.

45. Scott AM, Lee FT, Tebbutt N, Herbertson R, Gill SS, Liu Z, Skrinos E, Murone C, Saunder TH, Chappell B, Papenfuss AT, Poon AM, Hopkins W, Smyth FE, MacGregor D, Cher LM, Jungbluth AA, Ritter G, Brechbiel MW, Murphy R, Burgess AW, Hoffman EW, Johns TG, Old LJ. A phase I clinical trial with monoclonal antibody ch806 targeting transitional state and mutant epidermal growth factor receptors. Proc Natl Acad Sci U S A. 2007; 104: 40714076. 